\title{
Tribunal Federal de Recursos
}

\section{AGRAVO DE PETIÇÃO N. 6.862 SÃO PAULO}

Ilegitima a cobrança de contribuições de previdência, no que diz com profissionais que prestam serviços à firma, mas sem vinculo de emprêgo (advogados, engenheiros, empreiteiros).

\section{BERNARDES.}

Relator: O Exmo. Sr. Ministro Alfredo

Agravante: Instituto de Aposentadoria e Pensões dos Industriários.

Agravada: Companhia Cerâmica Vila Prudente S. A.

\section{ACÓRDÃO}

Vistos, relatados e discutidos êstes autos de Agravo de Petição n. ${ }^{\circ}$ 6.862, de São Paulo, agravante o Instituto de Aposentadoria e Pensões dos Industriários e agravada a Companhia Cerâmica Vila Prudente S.A.

Acorda a 2." Turma do Tribunal Federal de Recursos, por decisão da maioria, negar provimento ao agravo, tudo de conformidade com as notas taquigráficas em anexo, que dêste ficam fazendo parte integrante.

Custas ex-lege.

Rio, 3 de outubro de 1956. - CunHA VAsconcellos, Presidente. - CANDido Lobo, Relator ad hoc.

\section{RELATÓKIO}

O Exmo. Sr. Ministro Alrredo BernarDES - O Instituto de Aposentadoria e Pensões dos Industriários intenta executivo fiscal contra a Companhia Cerâmica Vila Prudente para cobrar-lhe contribuições não recolhidas acrescidas de juros e multa na importância de $\operatorname{Cr} \$ 89.105,50$.

Essas contribuições, segundo o autor, recaem sôbre os honorários dos advogados e engenheiros da Companhia a ré Djalma R.J. Magalhães, J.M. Camargo Aranha e H.C. Camargo Aranha e do engenheiro Djalma Lapage, bem como sôbre pagamentos fei- tos a Crescêncio Maneta, empreiteiro de serviços .

A executada, embargando o executivo, negou qualquer relação de emprêgo com os ditos advogados, engenheiro e empreiteiro que não estão subordinados à sua direção. Saneado o processo, realizado exame nos livros da ré e ouvidas as testemunhas de fls. 43 a 46, o MM. Juiz a quo proferiu sentença julgando improcedente o executivo pelas seguintes razões de direito: (fls. 68). O Instituto inconformado, agravou (fls. 73 a $77-$ ler), a executada confirmou (fls. 70 a 81 - ler), - Dr. Juiz manteve a decisão agravada, e nesta instância e Subprocuradoria Geral da República opinou nestes têrmos: fls. 88 ler). E' o relatório.

\section{VoTo}

O Exmo. St. Ministro Alfredo BerNARDES (Relator) - Nada tenho a acrescentar à douta sentença agravada. Por isto transcrevo-a no meu voto. como fundamentação dêste.

«Dou pela improcedência da ação.

Quanto aos advogados, sôbre cujos honorários foram calculadas contribuições de previdência social, entende êste Juízo que não são êles subordinados da ré e por isso mesmo não são seus empregados; conforme se viu da perícia e da prova testemunhal, tais advogados são profissionais liberais, com escritórios montados, prestando seus serviços não só a ré como a outros clientes; o sistema de remuneração - advocacia de partido - ou seja mediante pagamento de certa importância tixa mensal, ao invés de remuneração de cada serviço prestado, não é que irá tornar o advogado de partido em empregado da emprêsa para a qual preste serviços de advocacia.

Aliás, nem se compreende que advogados tais, pelo fato de prestarem seus serviços a várias firmas, se transformem em empregados de tôdas elas, simultâneamente; nem existiria em tal hipótese o vínculo de subordinação, caracteristico do empregado («sob dependência», art. $3 .^{\circ}$ da Consolidação das Leis do 
Trabalho; «assalaria e dirige a prestação pessoal de serviços», art. $\left.2 .^{\circ}\right)$.

«O objetivo principal das leis trabalhistas é a proteção a pessoa econômica e jurídicamente subordinada e não o trabalho em si, por ela prestado» esclarece José Martins Catharino (Tratado Jurídico do Salário fls. 86),

Aliás, essa é a orientação do Colendo Supremo Tribunal Federal (Revista dos Tribunais 196-524).

Não se nega a existência de advogados na situação de verdadeiros empregados, conforme bem esclareceu o Sr. Ministro Luiz Gallotti no citado julgamento, desde que esteja sujeito a honorários, vinculado a serviço da emprêsa, desempenhando trabalho integrado na sua engrenagem técnica, dirigido aos fins da emprêsa, ocorrendo então, a «integração objetiva), de que o professor Cotrin Neto (Contrato é Relação de Emprêgo, pg. 90).

Quanto ao engenheiro Dr. Djalma Lepage, a prova testemunhal evidencia que dita pessoa exercia altos cargos na administração da ré, sendo que, a par disso, executara eventualmente servicos técnicos para a ré, na qualidade de engenheiro, ora, em tais condições evidente também que não adquiriu a situação de empregado, pelos serviços eventuais que prestou, serviços êsses de natureza técnica, pois tão sòmente quando tais serviços são exercidos em «caráter permanente» ou em prazo superior a um ano (art. $7 .^{\circ}$ do Decreto n..$\left.^{\circ} 1.918\right)$, que se torna o contrato associado para efeito de pagamento de contribuições.

\section{Quanto a Crescencio Maneta.}

Improcede também a ação.

Dito indivíduo executou, mediante empreitada, um serviço de terraplenagem para a rế, no mês de agôsto de 1948, no valor de Cr\$ $400.068,50$.

O exeqüente, para exigir a contribuição, alega que dito individuo não é empregador inscrito no I.A.P.I. e que não recolheu as contribuiçôes devidas quanto a empregados que para êle trabalharam, pelo que a responsabilidade do pagamento recai sốbre a ré.

Não procede a exegese do exeqüente.

$\mathrm{Em}$ primeiro lugar porque evidenciado está que Maneta não é empregado da ré, tanto assim, que o pagamento não está na conta de salários, mas sim no título «Despesas de terraplenagem»; $\mathrm{cm} 2 .^{\circ}$ lugar porque montando o pagamento a elevada quantia de mais de $\mathrm{Cr} \$ \ldots \ldots \ldots \ldots$ em um mês, óbvio que engloba salários de muitos empregados ou então despesas com emprêgo de maquinaria ou de qualquer outra natureza; em 3.9 lugar porque $o$ exeqüente não citou dispositivo de lei que responsabilize a ré por contribuições não pagas por outro empregador que com ela contratou serviços de empreitada ou de outra natureza; na falta de dispositivo expresso, prevalece o preceito legal que responsabiliza pelo recolhimento o empregador (art. 30 do Decreto n.? 1.918) e esta qualidade não se transmite à ré pelo fato do legitimo empregador não haver recolhido as contribuiçôes devidas.

Aliás, certo ainda que se Maneta não está filiado ao I.A.P.I., nem por isso se poderá afirmar que as contribuições não foram recolhidas pois poderia êle estar inscrito em outro Instituto de Previdência Social; e mesmo se estivesse filiado no I.A.P.I. e se não houvesse recolhido as contribuições a responsabilidade ainda permanecia dêle, na qualidade de empregador.

Certo ainda que Maneta poderia não estar sujeito a inscrição em qualquer Instituto de Previdência Social, como por exemplo, se exercesse atividade ligada à agricultura, de modo que à falta de inscrição no I.A.P.I. não pode acarretar para a ré o ônus do pagamento das contribuições.

O fato é que o empreiteiro sòmente adquire a qualidade de empregado ou locador de serviços quando é subordinado ou vinculado ao empregador que o contratou, quando é econômicamente um fraco, quando então a empreitada passa a ser simples modo de pagamento (Rev. Forense, 94-584: Ar. Judiciário, 86-348, 92-86; Rev. dos Tribunais 187-44; 192-871 197-450 e 202-597).

Ocorre ponderar ainda que ao contratar uma empreitada ou qualquer outro serviço com terceiro, a ré não está obrigada por lei a verificar se êsses terceiros estão ou não filiados. como empregados no I.A.P.I.; cabe ao exeqüente verificar o fato e aplicar sanções aos infratores da lei, não sendo de justiça responsabilizar quem não tem culpa pelo evento.

Em vista do exposto e do que mais consta. dos autos, dou pela improcedência da ação, condenando o autor nas custas do processo.

Meu voto, pois, é negando provimento ao agravo para confirmar, na integra a sentença agravada, que concluitu pela improcedência da ação e condenou o autor nas custas. do processo.

\section{vото}

\section{(Vencido)}

O Exmo. Sr. Ministro Artur Marinho: Sr. Presidente, data venia do eminente Relator, dou provimento ao agravo.

Fazendo distinção, considero que um advogado, quando presta serviços permanentes, mediante remuneração, a determinado órgão. 
como no caso dos autos, sem que possa reservar-se a liberdade de aceitar ou não os encargos que the são conferidos, por isso que se desnatura o que é, na própria expressão literal, profissão liberal, percebe salário, no sentido abrangedor, e não honorários.

A concepção de honorários, tanto em linguagem comum como em sentido clássico, mesmo juridico, é que remunera serviço isolado prestado em causa. $E^{\prime}$ nesse sentido, por exemplo, que o art. 64, do Código de Processo Civil, alude a honorários. Êstes não se confundem com salário. Mas quando o advogado presta serviço permanente, o que percebe é salário. $\mathrm{O}$ advogado é um assalariado de classe alta, como profissional, mas assalariado no bom sentido da palavra.

Aparecem, às vêzes, dificuldades práticas. em dadas situações, quando um mesmo advo. gado presta serviços a diversas organizações. Este é outro assunto. Mas a própria legisla. ção trabalhista procura solucionar a situação, quando se trata de um mesmo empregado prestando serviço a váriós empregadores. Não é situação nova e imprevista na legislação trabalhista.

Por êsses motivos, embora a sentença do Dr. Juiz a quo esteja muito bem lançada, do ponto de vista formal e de exposição do convencimento de $\mathrm{S}$. Ex ${ }^{3}$, ponto de vista com o qual comungou o douto Relator, divirjo, com a devida vênia, de Sua Excelência.

\section{DECISÃO} (Julgamento da 2. ${ }^{*}$ Turma em 3 de
outubro de 1956)

Como consta da ata, a decisão foi a seguinte: Negou-se provimento, por maioria de votos, vencido o $\mathrm{Sr}$. Ministro Artur MARINHO. O Sr. Ministro CÂNDIDO LoBo votou com o Ministro Relator. Presidiu o julgamento o Exmo. Sr. Ministro Cunha VasCONCELLOS.

(Publicado no Diário da Justiça de 24 de fevereiro de 1959 - nas páginas ns. 735-6 apenso ao $\left.n,{ }^{\circ} 44\right)$. 